\title{
Formação continuada, \\ para quê?
}

Meyri Venci Chieffi*

Maria José Reginato**

*Pedagoga com pós-graduação em Supervisão e Currículo na PUC. Diretora do Ensino de 10 e 2으 Graus da Secretaria de Educação da Rede Municipal de Ensino de São Paulo, na gestão do prof. Paulo Freire; coordenadora de vários projetos no Cenpec e atual colaboradora meyri@cenpec.org.br

**Pedagoga. Coordenadora do Programa de Formação para Professores de 4a e 5 séries da Rede Municipal de Ensino, na gestão Paulo Freire; coordenadora de vários projetos no Cenpec e atual colaboradora zeze@cenpec.org.br
Resumo: A partir da descrição de quatro experiências de formação continuada de professores de redes públicas de ensino das quais as autoras participaram como formadoras, são identificadas algumas condições comuns que podem ser reconhecidas como responsáveis pela boa avaliação das experiências. As condições propostas são: prioridade na política educacional, adesão dos professores, participação nas decisões, envolvimento de expressivo número de profissionais e de diferentes instâncias do sistema, mudança nas condições de trabalho dos professores, formação contínua e sistemática com, no mínimo, dois anos de duração, prática dos profissionais como conteúdo da formação, movimento metodológico, lócus da formação, acompanhamento pelo sistema e avaliação contínua.

Palavras-chave: Formação. Participação. Autonomia intelectual. Condições de trabalho 
A raiz mais profunda da politicidade da educação se acha na educabilidade mesma do ser humano, que se funda na sua natureza inacabada e da qual se tornou consciente. Inacabado e consciente de seu inacabamento histórico, necessariamente o ser humano se faria um ser ético, um ser de opções, de decisão (FREIRE, 2014a, p. 108).

Entende-se por formação continuada aquela destinada aos profissionais que já estão no exercício da docência, em contraposição à formação inicial que forma os profissionais para o seu exercício. São duas práticas distintas que não se confundem e não se substituem, mas se complementam.

Por que os profissionais que exercem a docência precisam de formação? Primeiro porque, conforme Freire afirmava, o ser humano, enquanto ser social e histórico, é um ser finito, limitado, inconcluso e consciente de sua inconclusão:

Ressaltamos inicialmente a sua condição de ser histórico-social, experimentando continuamente a tensão de estar sendo para poder ser e de estar sendo não apenas o que herda, mas também o que adquire e não de forma mecânica. Isso significa ser o ser humano, enquanto histórico, um ser finito, limitado, inconcluso, mas consciente de sua inconclusão. Por isso, um ser ininterruptamente em busca, naturalmente em processo (FREIRE, 2014b, p. 23).

Assim, estamos inexoravelmente inseridos, de forma ingênua ou crítica, em processo contínuo de formação. Ao longo da história humana, a educação, como processo de conhecimento, de formação, de ensino e de aprendizagem, passou a fazer parte da existência humana, como qualquer outra produção cultural, como a linguagem ou a tecnologia. Aliás, o desenvolvimento da linguagem conceitual contribuiu imensamente para que a educação humana fosse para muito além do treinamento que se realiza com os outros animais. nessa condição que se funda a formação permanente. A formação é permanente porque, ao longo da história, o ser humano tomou consciência de que vivia, de que sabia e de que podia saber mais sobre si e sobre o mundo, que se transforma continuamente. Assim, o ser humano jamais parou de educar-se.

No caso específico dos professores, cuja atuação profissional é inserir as novas gerações, de forma crítica, no mundo do conhecimento produzido pela humanidade, a formação permanente é uma condição indispensável. Ela é um recurso de aprimoramento, de atualização dos profissionais, num mundo em constante movimento. A realidade se transforma rapidamente, produzindo fenômenos novos que precisam ser conhecidos, para uma maior compreensão do mundo e de seu funcionamento. 
A formação permanente de professores pode se dar por vários motivos: por iniciativa própria, em busca de aperfeiçoamento profissional, de respostas a indagações sobre questões advindas da prática de ensinar ou mesmo como forma de ascender na carreira. Mas, de um modo geral, boa parte das propostas de formação permanente é promovida pelo poder público, quando deseja implementar determinadas políticas ou programas, porque já se sabe que a formação permanente é condição fundamental para o sucesso de tais políticas ou programas.

É fato que qualquer reforma da estrutura e do currículo dos sistemas educacionais deve contar com o apoio dos professores, com sua atitude positiva em relação a capacitar-se para as mudanças pretendidas. Para que isso aconteça, no entanto, eles precisam identificar nas propostas de formação a serem realizadas, para além dos benefícios que trarão aos alunos e ao sistema educacional, os benefícios profissionais que elas trarão para a sua própria formação e para o seu desenvolvimento profissional. Este é um aspecto importante a ser considerado, uma vez que são eles que irão executar as referidas propostas, no exercício de sua profissão em sala de aula, com alunos concretos, em escolas concretas, inseridas em territórios com necessidades e problemas específicos.

Segundo Imbernón (2009), outro fator importante a se considerar nas propostas de formação permanente é o contexto político e social em que vivem os professores, pois:

\footnotetext{
o desenvolvimento das pessoas sempre tem lugar num contexto social e histórico determinado, que influencia sua natureza; isto implica analisar o conceito de profissão docente, a situação trabalhista e a carreira docente, a situação atual (normativa, política, estrutural...) das instituições educativas, a situação do ensino nas etapas infantil, ensino básico e ensino médio, a análise do atual alunado e a situação da infância e da adolescência nas diversas etapas numa escolarização total da população. [...] O contexto condicionará as práticas formativas e sua repercussão no professorado e, é claro, a inovação e a mudança (IMBERNÓN, 2009, p. 24).
}

Segundo o autor, vivemos no momento atual um paradoxo: há muita formação para os professores e poucas mudanças na qualidade do ensino. Os professores, de modo geral, parecem desmotivados e infelizes. Por que isso acontece? Ele levanta algumas hipóteses. Uma delas é a busca de alternativas meramente técnicas, realizadas pelos responsáveis pela formação dos professores das redes de ensino, como a solução para os problemas educacionais, avançando-se pouco no terreno das ideias, na discussão das práticas políticas que expressam uma formação baseada na 
liberdade, na reflexão, na cidadania e na democracia. Outra razão apontada por ele é a ausência de modelos relacionais e participativos nas práticas da formação, com o predomínio de políticas de formação transmissoras e uniformes, descontextualizadas dos problemas reais e concretos, com base em um professor que não existe, sem permitir a integração de outras formas de ensinar, de aprender, de se organizar, de ver outras identidades sociais, outras manifestações culturais, de permitir aos professores falarem e ouvirem-se entre si.

A pobreza das práticas de formação oferecidas aos professores é um dos grandes motivos da desmotivação docente que se observa, afirma Torres Santomé ${ }^{1}$ (2006 apud IMBERNóN, 2009, p. 36), já que existe “um tipo de política de atualização e incentivo do professorado que raras vezes tem repercussões sobre a qualidade dos projetos educativos nos quais ele está envolvido em seus centros" (p. 44), ou seja, são poucas as formações nas quais os professores se reconhecem e veem sentido, a ponto de mudar a prática que vêm desenvolvendo.

O mesmo enfoque dado ao valor da autonomia intelectual dos profissionais da educação é encontrado em Gimeno Sacristán e Pérez Gómez, quando afirmam:

o valor do pensamento em educação consiste mais em servir de instrumento para a deliberação constante em que toda a ação pedagógica deveria apoiar-se, desde as opções sobre estratégias de política educativa para todo o sistema escolar até as decisões práticas que, em momentos determinados, os professores tomam em suas aulas ou nas escolas. A utilidade do pensamento consiste em possibilitar a elucidação de problemas, mostrar contextos, fundamentar alternativas e valorizar retrospectivamente a prática. $O$ profissional do ensino, antes de ser um técnico eficaz, e mais do que ser um fiel servidor de diretrizes das mais variadas tendências num sistema submetido a controles técnicos que mascaram seu caráter ideológico, deve ser alguém responsável, que fundamenta sua prática numa opção de valores e em ideias que lhe ajudam a esclarecer as situações, os projetos e os planos, bem como as previsíveis consequências de suas práticas (SACRISTÁN; GÓMEZ, 2007, p. 10).

A análise e os argumentos usados por Freire, Torres Santomé, Imbernón, Sacristán e Pérez Gómez, com que interagimos em nossas leituras para escrever este artigo, nos desafiaram, como formadoras que somos, a olhar para a história de nossas experiências de formação com redes e identificar aquelas práticas formativas que mais fortemente produziram mudanças em escala, impactando a escola, a sala de aula e a aprendizagem dos alunos, para situar as condições de sucesso das mesmas.

1 TORRES SANTOMÉ, Jurjo. La desmotivación del professorado. Madri: Morata, 2006. 
Selecionamos, para isso, quatro experiências: duas delas enquanto integrantes da equipe central da Secretaria de Educação do município de São Paulo (1989-1992) e duas enquanto técnicas do Centro de Estudos e Pesquisas em Educação, Cultura e Ação Comunitária (Cenpec), na condição de instituição parceira para implementar projetos nas redes estaduais de São Paulo, Paraná e Goiás, no período de 1995 a 2005.

\section{AS QUATRO EXPERIÊNCIAS ESCOLHIDAS}

1a experiência - Reorientação curricular e formação de professores: duas faces da mesma moeda

No primeiro semestre de 1989, a Secretaria Municipal de Educação de São Paulo, durante a gestão do prof. Paulo Freire, definiu-se por uma reorientação curricular que possibilitasse às escolas criar projetos próprios ou aderir, com apoio de assessorias, ao projeto Ação Pedagógica da Escola pela via da Interdisciplinaridade. Um amplo programa de formação foi desenhado, de forma participativa, para dar sustentação à reorientação curricular. Entendiase que a reorientação curricular e a formação continuada de educadores se relacionavam como as faces da mesma moeda, sendo que o currículo desenvolvido nas escolas indicava os caminhos da formação e a formação qualificava o currículo das escolas. Sendo assim, uma ampla gama de ações de formação começou a ser desenvolvidas na rede.

Coube à Diretoria de Orientação Técnica (DOT) coordenar a proposta político-pedagógica junto aos Núcleos de Ação Educativa (NAEs), órgãos descentralizados da Secretaria de Educação. 0 objetivo dessa coordenação era definir as ações da política da forma mais participativa possível, procurando garantir a unidade dos princípios e ações, resguardando as diversidades regionais do município.

No primeiro ano, semanalmente, e nos anos posteriores, quinzenalmente, as equipes dos NAEs, que se constituíram de forma semelhante às da DOT, reuniam-se para planejar e avaliar as ações de reorientação curricular e as de formação continuada, desenvolvidas junto às escolas.

Educadores da DOT, assessorados por docentes da Universidade de São Paulo (USP), da Pontifícia Universidade Católica de São Paulo (PUC) e da Universidade Estadual de Campinas (Unicamp), responsabilizavam-se pela 
formação dos formadores de gestores, professores, funcionários, conselhos e grêmios escolares.

Na DOT, às sextas feiras, reuniam-se cerca de 400 educadores responsáveis por projetos ou grupos de formação, definidos como necessários para tornar a educação do município mais inclusiva: Ação Pedagógica da Escola pela via da Interdisciplinaridade, Projeto de Atendimento aos Professores de 5 a Série, Grupos de Formação com Profissionais de Educação Infantil, Ensino de $1^{0}$ e $2^{\circ}$ Graus, Educação de Jovens e Adultos, Projeto de Orientação Sexual, entre outros. Dessa forma, eram envolvidos diferentes educadores, de diferentes modalidades, níveis de ensino e áreas do conhecimento, como: professores de educação infantil, alfabetizadores de crianças, jovens e adultos, professores do $1^{0}$ e $2^{\circ}$ graus, coordenadores pedagógicos, diretores escolares, professores das salas de leitura, professores de educação especial e instrutores de bandas e fanfarras. 0 que trabalhar e como trabalhar junto aos educadores da rede foram os conteúdos da formação dos formadores, abrindo muito espaço para que os NAEs trouxessem seu fazer, seus acertos e erros, e para que a teoria tivesse o papel de auxiliá-los na compreensão e reorientação da prática. A intenção das equipes de DOT era, por meio de uma formação de formadores consistente, formar lideranças regionais que sustentassem o movimento de transformação que acontecia nas escolas. Era ponto de pauta planejar a formação de seus educadores, decidindo o que todos se comprometiam a desenvolver (pontos inegociáveis) e que aspectos poderiam ser trabalhados de acordo com a realidade local.

É importante considerar que a forma como os educadores da DOT encaminhavam sua formação se constituía uma referência para a formação nas regiões, e quanto mais refletida e planejada se caracterizava a formação dos formadores, mais consistente era a formação junto aos educadores das escolas. Descartava-se a concepção de professor multiplicador, pois entendia-se que somente o formador sujeito de sua prática poderia formar educadores capazes de gerar conhecimentos sobre sua prática. Vale ressaltar que cada projeto registrava seu caminho e refletia sobre suas aprendizagens, em publicações que constituíram referência na área de política pública de educação.

Este momento, bastante fecundo, reforçou nossa crença na dialogicidade como método, na participação como princípio, no coletivo como estratégia de trabalho. A redução significativa dos índices de evasão e retenção na rede, a realização de dois congressos municipais de educação, a produção de publicações com registros de toda a ação realizada, a apresentação dos trabalhos de formação 
por todas as equipes de DOT e NAEs na 6a Conferência Brasileira de Educação e o reconhecimento dos educadores, manifestado pelos altos índices de adesão às propostas, indicam que é possível, sim, fazer um trabalho de formação consistente em uma grande e exigente rede como a municipal de São Paulo.

\section{$2^{a}$ experiência - Projeto de Atendimento aos Professores de 5a série:} construindo alternativas para a superação da passagem da $4^{\mathrm{a}}$ para a $5^{\underline{a}}$ série

O Projeto de Atendimento aos Professores de 5á série, como vimos na experiência anteriormente relatada, desenvolveu-se na rede municipal de ensino de São Paulo, de 1989 a 1991, sob a coordenação das autoras deste texto. Tinha como objetivo intervir nesse que era um dos pontos de estrangulamento da escola de $1^{0}$ grau, reduzindo o alto índice de reprovação constatado em 1988 - 31,24\%.

Tínhamos clareza de que a formação dos docentes deveria subsidiá-los para uma reflexão crítica sobre sua prática, a partir do que efetivamente acontece na sala de aula, buscando a fundamentação teórica que servisse como referencial para que pudessem revê-la e superá-la. Como nossa equipe de coordenadores e professores que compunha a DOT 1ํ Grau havia recém-saído da escola, trazia muito frescas na memória as questões candentes dessa passagem de nível de escolaridade: o aumento significativo do número de professores, a diversidade de metodologias adotadas, a falta de integração entre os professores de $4^{\underline{a}}$ série e de $5^{\underline{a}}$ série, a exigência de organização e adaptação do aluno diante das novas e diversas solicitações, a falta de compreensão em relação às mudanças físicas, cognitivas, afetivas e sociais por que passam os alunos nesse período e a interferência desses fatores na relação professor-aluno. Assim, essas questões transformaram-se nos seguintes conteúdos temáticos da formação: As dificuldades no processo ensino-aprendizagem na $5^{\underline{a}}$ série; Quinta série: continuidade ou ruptura? Adolescências; A questão do conhecimento e as disciplinas curriculares; Disciplina em sala de aula; A avaliação da aprendizagem - como fazer?

Para desenvolver uma formação que realmente tivesse impacto na prática educacional e na aprendizagem dos alunos, optou-se por fortalecer a escola, por meio do grupo de professores de $5^{\underline{a}}$ série. Assim, a participação no projeto era por adesão da escola, após decisão dos professores, a qual se organizava, com eles, para a saída para os encontros, nos horários de trabalho, pleiteando professores substitutos nos NAEs ou organizando um calendário extra de aulas em outros períodos. Isso era feito após negociação 
com pais e alunos. Cada escola participava com quatro ou cinco professores de 5a série e com um a dois professores de 4ํㅡㄹ série.

Eram previstas duas fases na formação. A primeira previa oito encontros iniciais de quatro horas, um por semana. Nessa fase, os professores contavam com 12 horas a mais para a realização de atividades - tarefa na própria escola. Após os oito primeiros encontros, os professores deveriam elaborar uma proposta própria para a sua escola, com vistas a atender melhor os alunos e reduzir a retenção. A partir daí, a escola entrava na segunda fase da formação - de acompanhamento e de aprofundamento das temáticas propostas na primeira fase, por meio de encontros mensais de formação, de quatro horas, e de palestras e mesas-redondas com professores da universidade. Essa segunda fase durava um período de 13 meses, após o que as escolas eram acompanhadas pelos NAEs, culminando o trabalho com mostras regionais, para relatos e debate das boas práticas assumidas pelas escolas, ao final de 1991.

Procuramos imprimir na formação uma dinâmica que envolvesse os dados de realidade das escolas e dos professores. Para cada tema a ser abordado, os participantes, usando as 12 horas de atividades-tarefa, deveriam coletar dados de sua unidade escolar, de suas turmas, realizar entrevistas com alunos e colegas professores de $4^{\underline{a}}$ e $5^{\underline{a}}$ séries, com coordenadores pedagógicos, gestores e responsáveis pela sala de leitura, provocando um movimento interativo e de pesquisa desses professores, dentro das suas unidades escolares. Tais dados eram trazidos para o debate na formação e as hipóteses levantadas pelo grupo eram sempre confrontadas com referenciais teóricos.

O projeto começou em 1989, em uma região piloto (zona leste), com 12 escolas e 60 professores, e se estendeu para as demais regiões da cidade no decorrer desse tempo. A partir do projeto piloto, a expansão se deu sob a responsabilidade dos NAEs, com a nossa supervisão semanal.

Um resultado muito significativo desse trabalho de formação foi a permanência, em 1991, na regência de classe de 5a a série, por opção, da maioria dos professores envolvidos no projeto. Também nos pareceu significativo o número de adesões de professores da 5a série à Reorientação Curricular, por via da Interdisciplinaridade, em andamento na rede. Ao final de 1991, todas as escolas da rede haviam aderido ao projeto e a porcentagem de retenção nas $5^{\text {ass }}$ séries caiu dos 31, 24\% de 1989 para 16\% em 1991.

Podemos afirmar, a partir dessa experiência, que vale a pena apostar na autonomia e no compromisso dos professores para estudar a realidade de suas escolas e de seus alunos e transformá-la a partir do debate coletivo. 


\section{3a experiência - Projeto de Aceleração da Aprendizagem: \\ o trabalho com estudantes com defasagem idade-série nas séries finais do ensino fundamental}

Poucos anos depois, agora na qualidade de pesquisadores do Cenpec, fomos desafiadas, por solicitação das equipes gestoras das secretarias de educação dos estados citados, a conceber um projeto de correção do fluxo escolar para as séries iniciais e finais do ensino fundamental. Esse projeto tinha como objetivo a reintegração de crianças e jovens com defasagem idade-série ao percurso escolar estabelecido no sistema de ensino. 0 direito à educação de qualidade sempre norteou a ação do grupo e ajudou a definir a proposta pedagógica que embasou o material “Ensinar e Aprender”, elaborado para alunos e professores envolvidos no projeto. Além do material, o projeto previu um amplo programa de formação desenvolvido com as equipes pedagógicas dos órgãos regionais dessas redes. Os primeiros estados a desenvolver o projeto foram Paraná, São Paulo e Goiás.

Cabe ressaltar que uma importante questão que se coloca para as redes públicas dos estados ou mesmo de grandes municípios, como foi o caso das experiências anteriores, é como implementar políticas de formação continuada com professores de toda a rede, devido às dimensões geográficas e de pessoal dessas redes. Nesses casos, a opção pela formação de formadores é sempre uma boa estratégia para mobilizar um grande número de educadores, tendo sido essa a opção de tais estados.

Coube ao Paraná, o primeiro a desenvolver o projeto das séries finais do ensino fundamental, desenhar a estratégia de formação, que posteriormente foi utilizada em outros estados, acompanhar a produção do material "Ensinar e Aprender” e validá-lo. Assim como na rede municipal de São Paulo, o estado optou pela formação de formadores, vindos das equipes pedagógicas de todos os 32 órgãos regionais. Cada equipe regional era composta por professores das áreas do conhecimento, responsáveis pela formação dos professores locais, e por supervisores que se responsabilizavam pela formação dos gestores escolares, peças-chave no enraizamento do projeto na escola.

A formação dos professores das equipes regionais era feita por uma dupla composta por professor especialista e por pedagogo, para assegurar a consistência dos conteúdos curriculares e a unidade da proposta pedagógica. Essas escolhas constituíram aprendizagens que foram incorporadas à proposta de formação desenvolvida nos outros estados que, subsequentemente, desenvolveram o projeto. 
O estado de São Paulo aperfeiçoou a logística dos encontros e atendeu as 89 Coordenadorias Regionais de Educação (890 formadores) no trabalho de formação, envolvendo no processo, por adesão, todas as escolas da rede. Com a adoção do projeto e de outras medidas concomitantes, entre elas o estabelecimento dos ciclos de aprendizagem, o estado corrigiu o fluxo escolar de sua rede. Avançou também na socialização das experiências, organizando grandes seminários para reflexão e troca. Foi nesse processo que a Secretaria percebeu que a articulação da escola com outras instituições do território, como Ministério Público e os Conselhos Tutelares, seria fundamental para garantir a permanência na escola de alunos extremamente vulneráveis.

O estado de Goiás, por sua vez, elegeu para o projeto as 13 Subsecretarias Regionais de Ensino que apresentavam os maiores índices de alunos com defasagem idade-série, e avançou na proposta de acompanhamento das ações regionais, por parte da equipe central da Secretaria, indicando que formação e acompanhamento são ações que se complementam e se retroalimentam. Duplas pedagógicas da Secretaria visitavam as regiões regularmente e indicavam aspectos que deveriam ser trabalhados com maior ênfase pelos formadores do Cenpec. Esta secretaria também envolveu na formação, além dos formadores das subsecretarias, professores representantes das escolas. Os grupos mistos indicaram um caminho interessante para a formação.

As formações para a implementação dos projetos de correção do fluxo escolar nos indicaram que é possível enfrentar problemas crônicos da educação brasileira com vontade política e trabalho consistente. Indicaram também que para transformar a escola é necessário envolver um número significativo de educadores e que o uso de material didático não é impedimento para que a formação de professores se desenvolva na perspectiva de sua autonomia.

\section{4ํㅡ experiência - 0 Projeto Educação e Cidadania (PEC): garantindo o direito à educação de adolescentes em situação de internação provisória}

O desenvolvimento do Projeto Educação e Cidadania (PEC), realizado pelo Cenpec junto aos profissionais que atuavam nas unidades de internação provisória da Fundação do Bem Estar do Menor (Febem), hoje Fundação Casa, em São Paulo, de 2000 a 2005, é mais um exemplo da implementação de condições favoráveis a uma boa formação. 
A demanda da Febem para o Cenpec era de organizar a escolaridade prevista em lei, como um direito, para adolescentes a quem se atribuem atos infracionais que ficam sujeitos à internação provisória, aguardando sentença judicial, por um período de até 45 dias. 0 desafio era compor um currículo passível de ser desenvolvido com grupos móveis de alunos que entram ou saem diariamente da instituição. Para enfrentá-lo, organizamos um grupo misto, com estudiosos de vários campos do conhecimento, afins com a questão do adolescente infrator, como direito, antropologia, psicologia, sociologia, assistência social, além de técnicos e professores da Febem e da Secretaria de Educação do Estado de São Paulo e, ainda, pedagogos e especialistas das áreas do conhecimento do Cenpec. Foram meses de trabalho, pesquisas em teses, debates e entrevistas com técnicos da Febem e com os adolescentes internos, inclusive. Nesse período, elencamos algumas condições que considerávamos necessárias para que o projeto fosse bem implementado, pois ele não poderia depender apenas da boa vontade dos professores. Exigia estudo, planejamento, protagonismo, apoio. Assim, foram pleiteadas pelo grupo, junto à Secretaria de Educação, as seguintes medidas:

- A proposta pedagógica seria apresentada no evento da escolha de classes pelos professores da rede estadual, no início do ano letivo, para que pudessem optar conscientemente pelas classes da Febem, sabendo da existência do projeto e da necessidade de aderir a ele. Até então, as classes da Febem ficavam para os últimos professores da lista. Não era opção.

- A escolha dos professores pelas classes de internação provisória implicava a sua participação em um amplo programa de formação, de 248 horas, que envolvia também, com menor número de encontros, gestores, coordenadores pedagógicos, técnicos das unidades de internação provisória (psicólogos e assistentes sociais), a fim de se discutira proposta, sua fundamentação, as condições de implementação nas unidades, o papel de cada segmento profissional no contexto de mudança proposto para a Febem, na ocasião, e o material pedagógico elaborado para professores e alunos. A formação dos professores seria extensa, no decorrer do ano e não concentrada, de forma a permitir alternância de períodos de formação com períodos de trabalho nas unidades e, consequentemente, a avaliação do impacto da proposta nas unidades e a necessidade de reorientação da formação.

- A jornada desses professores seria de 40 horas na mesma unidade, a fim de que pudessem discutir o projeto, estudar e planejar o uso 
do material elaborado especificamente para ele e trabalhado nas formações.

- Os professores poderiam contar com o acompanhamento do Cenpec e de supervisores da Secretaria da Educação durante toda a implementação da proposta.

- O acompanhamento e a avaliação do projeto seriam participativos e envolveriam dois níveis: o horizontal (por segmento profissional) e o vertical (a unidade como um todo e as diferentes instâncias envolvidas).

Cabe esclarecer que o currículo adotado foi interdisciplinar e temático. Os temas foram estabelecidos a partir das entrevistas com os adolescentes e das pesquisas em teses específicas sobre o assunto, realizadas pelo grupo de trabalho (Febem, Cenpec, Secretaria da Educação, especialistas), a saber: Justiça e cidadania; Educação, uma ponte para o mundo; 0 trabalho em nossas vidas; Família e relações sociais e Saúde e cidadania. Os temas eram trabalhados na forma de oficinas diárias para atender até mesmo o aluno que ficasse apenas um dia na unidade de internação. Além dos cinco temas, foram elaboradas 11 oficinas culturais para serem trabalhadas no contraturno, em integração com os temas interdisciplinares: Letramento e alfabetização; Poesia; Contos; Jornal; Correspondência; Artes cênicas; Hora de se mexer; Música e movimento; Ponto de encontro; Jogos da vida; Educação ambiental. O PEC teve uma ampla repercussão na instituição e se tornou currículo oficial das unidades de internação provisória pela Resolução 109/2003 da Secretaria de Estado da Educação (SEE), sendo desenvolvido junto aos adolescentes nessa condição até os dias de hoje.

\section{O PORQUÊ DO SUCESSO DAS EXPERIÊNCIAS RELATADAS}

Observando as quatro experiências relatadas, que condições comuns podemos identificar como responsáveis pelos bons resultados alcançados, sendo elas distintas entre si?

- PRIORIDADE NA POLÍTICA EDUCACIONAL

Todas as ações de formação apontadas por nós consistiram prioridade de governo, relacionadas às metas que as administrações se propunham. 
Contavam com o apoio de diferentes setores do sistema para se viabilizar e eram alvo de acompanhamento e avaliação. Na Secretaria Municipal de São Paulo havia uma forte vontade política de transformar as escolas em espaços mais democráticos e inclusivos, com currículos que auxiliassem os alunos a entenderem criticamente a realidade. Da mesma forma, os programas de aceleração desenvolvidos constituíram prioridade para os estados envolvidos, uma vez que a correção do fluxo escolar de suas redes de ensino era meta de sua política educacional. Para a Febem, o PEC, no conjunto com outras ações, operacionalizaria a política do Novo Olhar, do estado de São Paulo, que pretendia mudar a cultura institucional opressiva, garantindo a dignidade e 0 direito à escolaridade aos adolescentes em conflito com a lei. Diante dessas evidências, pode-se afirmar que programas de formação que não contam com o aval político dos governos tendem ao esvaziamento e à pulverização.

\section{- ADESÃO DOS PROFESSORES}

Nas quatro experiências, a adesão dos professores à formação proposta esteve presente como condição real. A prática educativa muda apenas quando o professor quer modificá-la. Isso significa que a adesão aos programas de formação é condição indispensável para que venham a ter sucesso. Vimos que os professores aderem às propostas de formação quando estas respondem aos problemas que enfrentam no dia a dia da sala de aula. Quando os professores encontram caminhos para a solução de seus problemas, começam a mudar sua prática. São os avanços que percebem na sua própria atuação docente, com os alunos aprendendo, que os convencem da importância das mudanças. Quando essa ação é compartilhada com outros professores, mais as novas práticas se consolidam.

\section{- PARTICIPAÇÃO NAS DECISÕES}

Nas experiências citadas da SME de São Paulo, a participação era um dos princípios que alicerçava o trabalho. As equipes das várias instâncias da secretaria e dos NAES (Núcleos de Ação Educativa) definiram as prioridades, delinearam e desenvolveram as ações, o que explicaria, em boa parte, 0 alto grau de adesão às ações da política educacional naquele período. Nas experiências da Febem e da Aceleração da Aprendizagem, vale ressaltar a participação de diferentes segmentos na elaboração da proposta e dos materiais para professores e alunos, o que possivelmente contribuiu para a sua grande aceitação e utilização nos espaços institucionais e escolares. $\mathrm{Na}$ nossa avaliação, criar intencionalmente estratégias para aumentar os níveis de participação de todos os envolvidos nos programas de formação é 
condição para se ter a adesão dos docentes mais comprometidos e engajar, progressivamente, os demais no processo de democratização da educação.

- ENVOLVIMENTO DE EXPRESSIVO NÚMERO

DE PROFISSIONAIS E DE DIFERENTES INSTÂNCIAS DO SISTEMA

Outro ponto importante de participação a destacar, e também comum às quatro experiências elencadas, refere-se ao número de docentes e gestores envolvidos. Em todas elas, o número de participantes foi expressivo e envolveu redes inteiras ou boa parte delas. Além da quantidade dos envolvidos no público-alvo, é importante lembrar a sua composição, que contemplava todas as instâncias do sistema e dos responsáveis pela ação. Em nossa experiência com outros trabalhos de formação, vimos que aqueles limitados a poucos educadores ou a agrupamentos segmentados de gestores ou professores, ou mesmo a técnicos do sistema, apostando no efeito cascata, apresentam um potencial muito menor de impacto e de mudança. Os melhores resultados acontecem sempre quando professores, diretores, coordenadores pedagógicos e técnicos das secretarias têm espaços organizados de estudos, troca de experiências e debates, que provocam movimento de alteridade e perspectivas de construção coletiva.

\section{- MUDANÇA NAS CONDIÇÕES DE TRABALHO DOS PROFESSORES}

Nas quatro experiências, o poder público assumiu algumas condições estruturais consideradas fundamentais para que as mudanças desejadas ocorressem. Nas experiências da SME, por exemplo, os educadores participavam de encontros e cursos de formação fora da escola, no horário de trabalho, e ainda recebiam 10/12 horas-atividade semanais para estudos coletivos, nas escolas, a fim de elaborarem projetos próprios para suas unidades escolares, visando à melhoria da qualidade do ensino. Essas horas também eram dedicadas a reuniões de discussão da prática e planejamento de ações. No projeto Educação e Cidadania, os professores passaram a contar com 40 horas semanais de trabalho nas mesmas unidades de internação provisória, para poder planejar, acompanhar e avaliar continuamente o projeto, em conjunto com coordenadores pedagógicos, técnicos (psicólogos e assistentes sociais) e gestores. Contavam também com horas de formação fora das unidades. Da mesma forma, nos projetos de Aceleração de Aprendizagem, instalou-se o horário de trabalho coletivo remunerado nas escolas, prática essa não comum naquela ocasião. As classes eram formadas por até 25 alunos e os professores as acompanhavam por um ciclo de dois anos, sendo apoiados por um amplo programa de formação e material elaborado especialmente para esse universo de alunos. 
Outras condições, relacionadas à ampliação do repertório dos professores e à valorização e reconhecimento do seu trabalho, também contribuíram para o sucesso dessas experiências, como a realização de formação em espaços culturalmente relevantes do estado ou do município, o acesso a jornais, publicações, periódicos e eventos promovidos pelos projetos e a participação dos docentes em seminários e congressos.

- FORMAÇÃO CONTÍNUA E SISTEMÁTICA COM, NO MÍNIMO, DOIS ANOS DE DURAÇÃO

Todas as ações de formação citadas foram contínuas, duradouras e sistemáticas. Desenvolveram-se por períodos entre dois e quatro anos, apresentando desenhos de formação com encontros regulares, agendados previamente. A nossa experiência mostra que formações com períodos menores de dois anos podem causar algum impacto junto aos docentes, mas raramente se consolidam, com deslocamentos significativos na prática desenvolvida pelas escolas.

\section{- PRÁTICA DOS PROFISSIONAIS COMO CONTEÚDO DA FORMAÇÃO}

Nas formações aqui relatadas, o objeto de estudo e trabalho era a prática dos professores. Por isso tinham foco no aluno, no processo ensinoaprendizagem, na relação professor e aluno, nos conteúdos curriculares, na avaliação, no planejamento. A prática era o conteúdo. A forma como os professores trabalhavam, as produções e reações dos alunos à proposta do projeto, as conquistas e as dificuldades encontradas e os referenciais teóricos necessários eram ponto de pauta, organizada devidamente para que houvesse sempre voz para todos, questionamentos, estudos e elaboração de propostas para a sala de aula e para a escola.

O processo de formação tinha o caráter de aprendizagem para os professores, cabendo aos formadores assumirem o papel de parceiros deles, ajudandoos no diagnóstico dos problemas de sala de aula, compartilhando reflexões e estudos sobre esses problemas, assim como assessorando na elaboração conjunta de propostas de encaminhamentos pedagógicos individuais ou coletivos para tais problemas, buscando e apresentando tanto a fundamentação teórica necessária para os problemas abordados como as experiências docentes já realizadas para lidar com os mesmos problemas. Dessa forma, os professores aprendiam "reinterpretando os significados da cultura, mediante contínuos e complexos processos de negociação, a partir da prática” (SACRISTÁN; GÓMEZ, 2007, p. 96). 


\section{- MOVIMENTO METODOLÓGICO}

Um movimento metodológico comum perpassou as ações de formação referidas, apesar das diferentes dimensões dos projetos. Assim, tanto no que se referia à elaboração e desenho do projeto como um todo como ao desenvolvimento dos encontros de formação, alguns momentos dialógicos estiveram sempre presentes. 0 primeiro momento era de diagnóstico inicial da realidade e de levantamento de hipóteses para o problema em questão. Esse momento era seguido por outro, que buscava respostas para essas hipóteses por meio da ampliação dos conhecimentos dos professores a respeito do problema identificado, trabalhando-se, com seriedade, conteúdos que reforçavam ou questionavam práticas desenvolvidas, apresentando novas possibilidades de compreensão e de ação. Um terceiro momento era de sistematização das aprendizagens, com momentos de síntese e de volta à realidade, de transformação da prática, com o objetivo claro de melhorar a qualidade do trabalho com crianças, adolescentes e jovens.

Essa forma de trabalho possibilita a apreensão de elementos importantes, presentes nas diferentes redes de ensino e instituições, e é fundamental para que as ações de formação respondam às necessidades dos educadores, façam sentido para eles e estabeleçam nexos com seu universo teórico e prático. O movimento dialógico, que explicita claramente o objetivo da ação, seus pontos de chegada e considera os educadores como sujeitos e parceiros no desenvolvimento das ações, cria cumplicidade e compromissos coletivos que favorecem a transformação.

\section{- LÓCUS DA FORMAÇÃO}

Nos quatro projetos de formação relatados, foi considerada importante e complementar a formação na escola e fora dela, contemplando-se estratégias diversificadas. Fora da unidade escolar, os mais frequentes foram os agrupamentos por área de ensino ou função desempenhada pelos profissionais. Eram os momentos de, com seus pares, professores e gestores aprofundarem-se nas questões curriculares e discutirem seu papel no universo escolar. Esses encontros desdobravam-se nos horários de formação nas escolas e a eles articulavam-se, agora, com o objetivo de planejar, de forma coletiva, o trabalho na unidade escolar. Os seminários para aprofundamento de temas fizeram parte dos desenhos e mostras de trabalho, e possibilitaram a sistematização dos avanços das escolas e a sua socialização e divulgação. Merecem destaque os dois congressos municipais de educação, realizados em diferentes espaços do Anhembi, que combinaram falas de reconhecidos 
intelectuais da educação do país com relatos de práticas das escolas e contaram com a participação de milhares de educadores, em cada um deles. A nosso ver, a dicotomia formação na escola ou fora dela é falsa, na medida em que possuem propósitos distintos e complementares.

\section{- ACOMPANHAMENTO PELO SISTEMA E AVALIAÇÃO CONTÍNUA}

Todos os quatro projetos apresentaram algum tipo de acompanhamento para apoio e avaliação contínua pelas instâncias do sistema. Na Secretaria Municipal de São Paulo, o acompanhamento era feito pelos Núcleos de Ação Educativa (regionais), que subsidiavam as escolas (gestores e professores), prestavam assessoria e levavam as questões importantes aí encontradas para discutir nos encontros de formação. As avaliações ocorriam semestralmente, em grandes coletivos, responsáveis também pelo replanejamento das ações. Nas quatro experiências, os momentos de formação previam levantamento de dados para a avaliação contínua do trabalho. Em Goiás, educadores da equipe central da Secretaria de Educação acompanhavam o trabalho em todas as subsecretarias regionais e, na Febem, escolheram-se algumas unidades de internação provisória para serem acompanhadas diretamente pela equipe coordenadora do projeto, criando-se modelos de acompanhamento que foram incorporados pelas equipes regionais.

Os dados colhidos, de caráter quantitativo e qualitativo, eram trabalhados pela própria equipe da formação e por educadores especializados em processos avaliativos. Nossa experiência mostra que quanto mais a avaliação se aproxima de um modelo participativo, que garanta a escolha dos pontos que serão acompanhados/avaliados, a agilidade na coleta dos dados e a análise coletiva desses dados, maior possibilidade terá de cumprir com sua função essencial de retroalimentar a formação e redirecionar as ações. Do contrário, poderá constituir somente uma coleção de informações para preencher relatórios burocráticos.

\section{CONSIDERAÇÕES FINAIS}

Considerando as condições expostas nas experiências relatadas, podemos afirmar que elas corroboram as hipóteses dos autores citados (TORRES SANTOMÉ, 2006; IMBERNÓN, 2009; SACRISTÁN; GÓMEZ, 2007) sobre as condições necessárias para uma formação efetiva, que transforme a realidade das salas de aula e das escolas. Podemos verificar que elas não têm natureza 
meramente técnica, mas envolvem discussão de ideias e de práticas políticas baseadas na liberdade, na cidadania e na democracia. Essas questões nortearam sempre os projetos citados, sendo objeto de estudo e debate no decorrer dos encontros de formação. Além disso, perpassa todas elas um forte caráter participativo, o que garante a adesão massiva dos envolvidos e permite trazer para a formação o contexto dos problemas reais e concretos vividos por aqueles que fazem a educação acontecer, diariamente, em todas as instâncias do sistema, promovendo a devida interação entre elas.

É de responsabilidade do poder público produzir as condições para que determinada política de educação seja implementada e se sustente nas redes de ensino. Esse fato é particularmente relevante no momento atual da educação brasileira, considerando-se a recente aprovação do Plano Nacional de Educação (PNE), que mobilizou amplo processo de participação dos profissionais da educação e da sociedade civil brasileira, tendo em vista um projeto democrático de país. O PNE prevê mais investimentos na educação e uma série de mudanças nas práticas dos sistemas educacionais, visando à melhor qualidade do ensino. Cabe lembrar que o PNE determina prazo para que todos os estados e municípios também elaborem os seus planos, de forma participativa, em consonância com seus princípios e metas.

Nesse contexto, é importante reafirmar que a adesão dos profissionais da educação às novas políticas só se dará pela compreensão da sua intencionalidade e pelo engajamento consciente às novas práticas propostas.

Sem compreender o que se faz, a prática pedagógica é mera reprodução de hábitos existentes, ou respostas que os docentes devem fornecer a demandas e ordens externas. Se algumas ideias, valores e projetos se tornam realidade na educação é porque os docentes os fazem seus de alguma forma: em primeiro lugar, interpretando-os, para depois adaptá-los. Já é uma crença bastante comum que os professores/as ou qualquer agente educativo são mediadores inevitáveis entre os ideais e as práticas, entre os projetos e as realidades. Apenas na medida em que cada um tenha claros esses projetos e essas ideias, pode ser um profissional consciente e responsável (SACRISTÁN; GÓMEZ, 2007, p. 9).

É importante também reafirmar que a vontade política dos governos deve se traduzir em ações que motivem e mobilizem os professores, os gestores e técnicos em ações conjuntas e compartilhadas de diagnóstico, de planejamento, de desenvolvimento de práticas de ensino e de avaliação, além de oferecer condições de trabalho, como horas de estudo coletivo, número adequado de alunos por sala, apoio e assessoria aos professores e remuneração correspondente. 
Reconhecemos que não é simples nem fácil abranger redes inteiras em formação, dadas as questões financeiras, operacionais e de escala, tampouco desenvolver modelos participativos. Isso exige uma profunda crença nos valores democráticos e na emancipação humana, o que implica persistência, tempo e continuidade. No entanto, sem tais investimentos, nada acontece de fato e as propostas se esvaziam e não conseguem se enraizar. 0 que temos vivido nos diferentes momentos da vida de formadoras tem nos mostrado que quando as administrações assumem esses valores democráticos, as políticas educacionais se implementam com excelentes resultados, conforme indicamos nas experiências relatadas.

Por outro lado, o que também temos vivido como formadoras de professores da rede pública é o profundo descaso com a história dessas redes e com as políticas até então desenvolvidas. Mudanças de governo e até mesmo de equipes dirigentes, dentro do mesmo governo, têm, muitas vezes, interrompido interessantes avanços na direção da democratização e da qualidade do ensino, num incessante reinventar da roda, desrespeitando o esforço coletivo empreendido até então pelos que fazem a educação no dia a dia. Compromissos assumidos pelas novas administrações durante as campanhas eleitorais com grupos privados, o desejo de imprimir marca própria em projetos novos, a formação de equipes despreparadas ou não comprometidas com a educação pública de qualidade têm sido algumas das razões para a não continuidade de boas políticas. Nesse sentido, o Plano Nacional de Educação pode significar uma ruptura com esse estado de coisas, norteando as políticas regionais e locais, de forma que fortaleçam os princípios de uma educação realmente pública e de qualidade, não sujeita às vicissitudes de diferentes administrações, partidos ou mercado.

A atual descrença dos professores nas formações continuadas advém exatamente das constantes mudanças, das péssimas condições salariais e de trabalho, do desrespeito por jogarem sobre seus ombros a responsabilidade pelo fracasso do sistema. Uma administração pública que respeita os professores cria condições para que a política a ser implementada aconteça de fato. Isso implica autonomia da escola para reorganização de horários de trabalho, mantendo o corpo docente mais tempo na escola, compensando o salário que recebe pelo trabalho em duas ou três unidades. Significa estudo coletivo para que o próprio grupo decida as propostas pedagógicas para sua escola e os encaminhamentos mais adequados para levar aquela proposta adiante, inclusive contando com recursos para buscar uma assessoria na universidade ou centros de pesquisas comprometidos com a educação 
pública, com a democracia e com a população desfavorecida. Significa facilitar a comunicação direta e a distância com outros professores da rede para trocar, relatar experiências, por meio de encontros de formação, mostras de trabalho ou congressos da rede e formação de grupos e comunidades virtuais. Significa formar, concomitantemente à formação dos professores, os gestores das escolas e do sistema para acolher, apoiar e acompanhar o trabalho docente.

Para finalizar, retomamos Imbernón (2009), que afirma a necessidade de uma reestruturação moral e intelectual na educação, com o objetivo de tornar os professores protagonistas de sua formação, devolvendo-lhes a dignidade e o controle sobre seu processo de trabalho, aumentando o seu autoconceito e seu status trabalhista e social. A implementação da reestruturação moral a que ele se refere visa resgatar o compromisso dos professores com os alunos e com a sociedade e a reestruturação intelectual visa à assunção de posturas críticas, para que se possa "recuperar o que uma vez se sonhou e não se alcançou e sonhar de novo” (IMBERNÓN, 2009, p. 36). 


\section{Continuing education: what for?}

Abstract: Starting from the description of four teachers' continuing education experiences in public school system in which they participated as coaches, they identify some common conditions that can be acknowledged as responsible for the good evalution of the experiences. These are the proposed conditions: priority to education policy, adherence of teachers, participation in decisions, involvement of a significant number of professionals and from different instances of the system, changing in teachers' working conditions, continuing and systematic education during at least two years, professional practice as education content, methodological movement, locus of education, follow-up by the system and continuing evaluation.

Keywords: Education. Participation. Intellectual autonomy. Working conditions. 
REFERÊNCIAS

FREIRE, Paulo. Pedagogia da autonomia. São Paulo: Paz e Terra, 2014a. Política e educação. São Paulo: Paz e Terra, 2014b.

IMBERNÓN, Francisco. Formação permanente do professorado: novas tendências. São Paulo: Cortez, 2009.

SACRISTÁN, José Gimeno; PÉREZ GÓMEZ, Angel. Compreender e transformar o ensino. Porto Alegre: Artmed, 2007.

RECEBIDO: Março de 2015.

APROVADO: Abril de 2015. 